\title{
One-Step Synthesis of Bimetallic Cobalt-Palladium Nanoparticles and a Carbon Support Based on Pyrolyzed Chitosan
}

\author{
M. N. Efimov ${ }^{a} *$, D. G. Muratov ${ }^{a}$, A. A. Vasiliev ${ }^{a}$, and G. P. Karpacheva ${ }^{a}$ \\ ${ }^{a}$ Topchiev Institute of Petrochemical Synthesis, Russian Academy of Sciences, Moscow, 119071 Russia \\ *e-mail:efimov@ips.ac.ru
}

Received November 16, 2020; revised November 16, 2020; accepted November 19, 2020

\begin{abstract}
A procedure is proposed for synthesizing monometallic (Co, $\mathrm{Pd})$ and bimetallic $\mathrm{Co}-\mathrm{Pd}$ nanoparticles immobilized in a carbon support based on pyrolyzed chitosan. A feature of the procedure is the simultaneous formation of metal nanoparticles and a carbon support during the heat treatment of a precursor based on a joint solution of a polymer and metal compounds under the effect of IR radiation. The phase composition, morphology of samples, and structural features of the carbon support are shown, depending on the nature of the metals that are used.
\end{abstract}

Keywords: metal-carbon nanocomposites, cobalt-palladium, IR radiation, chitosan, bimetallic nanoparticles

DOI: $10.1134 / \mathrm{S} 003602442109003 \mathrm{X}$

\section{INTRODUCTION}

Developing ways of synthesizing and producing bimetallic nanoparticles is a subject of interest to many scientific groups [1]. Two-component metal systems show improved functional properties, relative to monometallic analogs $[2,3]$. They find application in catalysis, sensor applications, energy storage, biomedical technologies, and other fields [1, 4-7]. Bimetallic systems are often used to reduce the cost of synthesized materials in which a more affordable metal is used along with a noble one while preserving catalytic properties $[8,9]$. On the other hand, the use of noble metal nanoparticles in bimetallic systems ensures the effectiveness of such materials as catalysts of chemical reactions $[10,11]$.

A traditional way of obtaining metal nanoparticles fixed on a support is the deposition of metal nanoparticles or compounds on a finished support of oxide or carbon [1, 12]. Oxide supports (e.g., $\mathrm{Al}_{2} \mathrm{O}_{3}, \mathrm{SiO}_{2}$, $\mathrm{TiO}_{2}$ ) are used most frequently, due to their availability and relatively low cost. These supports are capable of positively affecting the activity and selectivity of metal catalysts [13]. Under some conditions, however, they can be unstable and negatively affect the activity of the catalyst [14]. In addition, it is often impossible to recover active metal particles for reuse when using oxide supports. (This is especially important for noble metals, due to their cost.) The use of carbon supports is in some cases therefore promising, due to the resistance of such supports to acidic and alkaline media, elevated temperatures, as well as controlled porosity and the possibility of obtaining such supports in differ- ent forms (granules, fibers, powder) [15]. It should also be noted that the properties of carbon supports can be adjusted by changing their structure and morphology, and by modifying their surfaces with functional groups [16, 17]. In addition, carbon supports allow us to extract metal from spent catalysts by burning them in air. We can therefore obtain carbon materials with the required structural and functional characteristics, both at the stage of preparing such supports and when selecting the required carbon-containing precursor.

In this work, we propose a procedure for the in situ formation of bimetallic Co-Pd nanoparticles during the pyrolysis of a metal-polymer precursor based on chitosan. Chitosan is an aminopolymer obtained through the partial deacetylation of chitin, a naturally occurring polysaccharide. Chitosan is therefore a promising substitute for synthetic polymers in the synthesis of metal-carbon nanocomposites with various functional properties.

As a rule, metal nanoparticles fixed on a carbon support are obtained through a separate stage of metal deposition (e.g., impregnation with a solution of metal compounds, followed by reduction, laser deposition or deposition from the vapor phase) [18, 19]. In [20], we proposed a procedure for the simultaneous production of metal nanoparticles and a carbon support, in which a mixture of a carbon-containing precursor and metal compounds is subjected to heat treatment. This approach omits an additional stage of the formation of 
a carbon support and provides a large selection of carbon-containing precursors consisting of both synthetic and natural polymers, allowing us to adjust the structure and properties by changing the conditions of synthesis.

The aim of this work was to study the formation of monometallic $\mathrm{Co}$ and $\mathrm{Pd}$ nanoparticles, along with bimetallic $\mathrm{Co}-\mathrm{Pd}$ nanoparticles in a carbon matrix based on pyrolyzed chitosan.

\section{EXPERIMENTAL}

In this work, we used chitosan $\left(\mathrm{C}_{6} \mathrm{H}_{11} \mathrm{NO}_{4}\right)_{n}\left(M_{\mathrm{w}}=\right.$ $500 \mathrm{kDa}$; degree of deacetylation, $\sim 83 \%$ ) (Bioprogress, Russia), acetic acid $\mathrm{C}_{2} \mathrm{H}_{4} \mathrm{O}_{2}(99.8 \%)$, dimethylformamide $\mathrm{C}_{3} \mathrm{H}_{7} \mathrm{NO}$ (reagent grade), cobalt acetylacetonate $\mathrm{Co}\left(\mathrm{C}_{5} \mathrm{H}_{7} \mathrm{O}_{2}\right)_{2}$, and palladium acetate $\mathrm{Pd}\left(\mathrm{CH}_{3} \mathrm{COO}\right)_{2}$. The polymer was dissolved in a $2 \%$ solution of acetic acid in bidistillate. Metal compounds were dissolved in dimethylformamide, due to their poor solubility in water. The required amount of metal $(10 \mathrm{wt} \%)$ was calculated in relation to the carbon in the polymer. For composites with bimetallic Co-Pd particles, the total amount of metal relative to carbon in the polymer was also $10 \mathrm{wt} \%$. The atomic ratio of metals was $9: 1$. After complete dissolution of the components, the solutions of the polymer and metal compounds were mixed together and sonicated for $30 \mathrm{~min}$. The combined solution was dried to a constant weight at $80^{\circ} \mathrm{C}$. The resulting film was crushed and subjected to thermal treatment under the influence of IR radiation for $2 \mathrm{~min}$ at $700^{\circ} \mathrm{C}$. The heating rate was $50 \mathrm{~K} / \mathrm{min}$. The resulting powder was labelled depending on the metal that was used: $\mathrm{CS}-\mathrm{Co}$, $\mathrm{CS}-\mathrm{Pd}$, and $\mathrm{CS}-\mathrm{Co}-\mathrm{Pd}$.

Solutions were subjected to ultrasonic treatment using an MEF93.T homogenizer (MELFIZ Ultrasound, Russia). The phase composition and structure of the nanocomposites were studied at room temperature on a Difray-401 X-ray diffractometer using $\mathrm{Cr} K_{\alpha}$ radiation. The size distribution of coherent scattering regions (CSRs) was calculated according to Selivanov and Smyslov [21]. The morphology of the samples was studied via transmission electron microscopy on a JEM-2100 electron microscope (JEOL, Japan). The size of metal nanoparticles was determined from electron microscopic images, and the size distribution histograms were plotted using the DEAM software [22]. Raman spectra were recorded on a Renishaw InVia Reflex unit with a wavelength of $405 \mathrm{~nm}$ and power of $<0.5 \mathrm{~mW}$.

\section{RESULTS AND DISCUSSION}

Our approach to the simultaneous formation of bimetallic $\mathrm{Co}-\mathrm{Pd}$ nanoparticles and carbon supports based on pyrolyzed chitosan allows us to reduce the number of stages of preparing metal-carbon nano- composites. IR radiation used for heat treatment of the material can greatly reduce the periods of heating and holding at a given temperature, thereby shortening the time needed for the synthesis of metal-carbon nanocomposites $[6,23]$. During the pyrolysis of chitosan, it is carbonized into a material with a graphitelike structure [6, 24]. Among the products of chitosan pyrolysis are hydrogen and carbon dioxide, which contribute to the reduction of metals.

We synthesized samples of three compositions: CS-Co, CS-Co-Pd, and CS-Pd. The first two samples with only one metal were prepared to compare the structural characteristics of monometallic particles and bimetallic Co-Pd nanoparticles, and to study the effect each metal had on the structure and morphology of the carbon support that formed simultaneously with metal nanoparticles.

To study changes in the phase composition and structural characteristics of metal-carbon nanocomposites, the samples were subjected to XRD. Figure 1 shows the diffraction patterns of three samples: CS$\mathrm{Co}, \mathrm{CS}-\mathrm{Pd}$, and $\mathrm{CS}-\mathrm{Co}-\mathrm{Pd}$.

As can be seen from the figure, all three diffractograms contain a halo with a maximum in the region of $\sim 39^{\circ}$ that corresponds to $d_{002}$ plane of graphite (i.e., the halo characterizes the structural features of the nanocomposites' carbon matrix). In the diffraction pattern of the CS-Co nanocomposite, the sample matrix has the most pronounced maximum at a higher intensity and smaller half-width, indicating a higher degree of polymer carbonization. This effect could be due to the effect cobalt nanoparticles have on the carbon matrix as it forms. Along with other metals $(\mathrm{Fe}, \mathrm{Ni})$, cobalt raises the degree of graphitization, converting amorphous carbon into graphite [6, 25]. This peak is pronounced least for the CS-Pd nanocomposite and is observed as a wide halo, since the presence of palladium does not raise the degree of graphitization appreciably. In addition, the diffraction pattern of the CS-Pd nanocomposite contains peaks at $61.2^{\circ}, 71.8^{\circ}$, and $112.8^{\circ}$ that correspond to the palladium phase. Comparing the phase compositions of the mono- and bimetallic systems (CS-Co and $\mathrm{CS}-\mathrm{Co}-\mathrm{Pd}$ ), we observe a shift toward smaller angles of the peaks related to the cobalt phase with values of $67.9^{\circ}, 80.4^{\circ}$, and $132.4^{\circ}$ to $67.4^{\circ}, 79.2^{\circ}$, and $130.4^{\circ}$.

Table 1 presents values of lattice parameter $a$ of the metal phase for each sample. The lattice periods are 0.3538 and $0.3888 \mathrm{~nm}$ for the CS-Co and CS-Pd samples, respectively. For the CS-Co-Pd sample, the lattice period is $0.3570 \mathrm{~nm}$. Based on the change in the lattice period for the $\mathrm{CS}-\mathrm{Co}-\mathrm{Pd}$ sample relative to CS-Co, we may state a cobalt-based Co-Pd solid solution formed. Determining the lattice parameter 


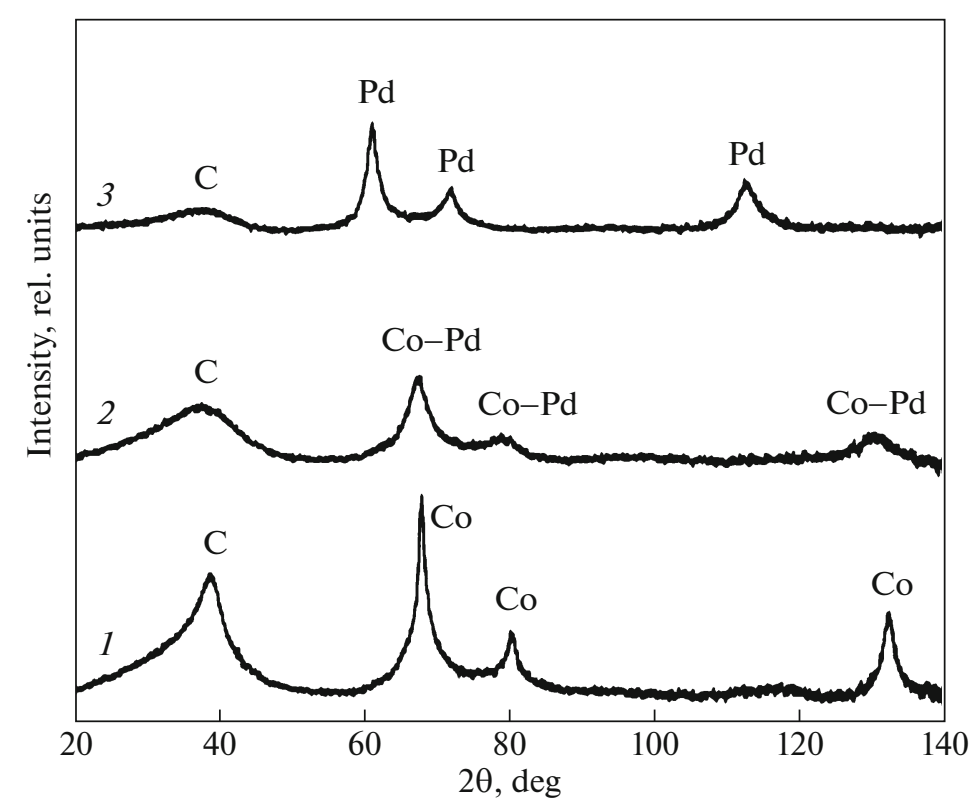

Fig. 1. Diffraction patterns of samples of metal-carbon nanocomposites: (1) CS-Co, (2) CS-Co-Pd, (3) CS-Pd.

for nanoparticles of a solid solution as in [26, 27], we estimated the ratio of the components in it to be Co $: P d=93: 7$.

Thus, our analysis has shown that nanoparticles of a solid solution based on cobalt are mainly formed. The difference in composition could be due to the formation of very small nanoparticles of a palladiumbased solid solution. Because of the low relative content of palladium in the precursor, this resulted in low intensity and strong broadening of the reflections of this phase in diffractograms, as was indicated by the asymmetry in the region of small reflection angles of plane (111) of the Co-Pd solid solution based on the cobalt lattice.

The CSR sizes of the metal phase were calculated for all samples using data from XRD data. It was found that the CS-Co nanocomposite contained the largest crystallites of the metallic phase, with a size of $7 \mathrm{~nm}$. It should be noted that adding 10 at $\%$ palladium reduced the size of crystallites to $4 \mathrm{~nm}$. CS-Pd nanocomposites were also characterized by smaller crystallites $4 \mathrm{~nm}$ in size.

The nature of the size distribution of nanoparticles was also confirmed by analyzing TEM micrographs of the samples. Figure 2 presents TEM micrographs for the CS-Co, CS-Co-Pd, and CS-Pd samples. Insets in the micrographs show the nanoparticle size distribution histograms. As can be seen from the figures, the largest nanoparticles were characteristic of the nanocomposite containing only cobalt. Nanocomposites containing palladium in the composition of mono- or bimetallic nanoparticles were characterized by smaller sizes ( 5 and $6 \mathrm{~nm}$, respectively) of these nanoparticles. Table 1 shows the values of the lattice parameter $a$ metal phase and average particle sizes obtained using the results from XRD and TEM for each sample.

As can be judged from the micrographs, the morphology of the carbon matrix is different for all three samples. A common feature of the materials is the high amorphousness of the carbon matrix, which contained mono- and bimetallic nanoparticles with sizes of mainly $5-8 \mathrm{~nm}$. At the same time, a considerable number of ordered graphite-like carbon structures is observed in the samples containing cobalt, while no similar structures are found in the presence of monometallic palladium nanoparticles. It should also be noted that an increased content of large nanoparticles is observed in these formations. The formation of large Co nanoparticles helps activate processes of carbon structurization at the interface with them, due to cycles of carbon dissolution in the metal-exceeding the solubility limit-precipitation of an ordered graphite-like phase. This continues until each particle forms a dense carbon shell around itself, preventing continu-

Table 1. Results from XRD and the average values of nanoparticle size for $\mathrm{CS}-\mathrm{Co}, \mathrm{CS}-\mathrm{Co}-\mathrm{Pd}$, and $\mathrm{CS}-\mathrm{Pd}$ samples

\begin{tabular}{l|c|c|c}
\hline \multicolumn{1}{c|}{ Sample } & $D_{\mathrm{CSR}}, \mathrm{nm}$ & $D_{\mathrm{TEM}}, \mathrm{nm}$ & $a, \mathrm{~nm}$ \\
\hline CS-Co & 7 & 8 & 0.3538 \\
CS-Co-Pd & 4 & 6 & 0.3570 \\
CS-Pd & 4 & 5 & 0.3888 \\
\hline
\end{tabular}



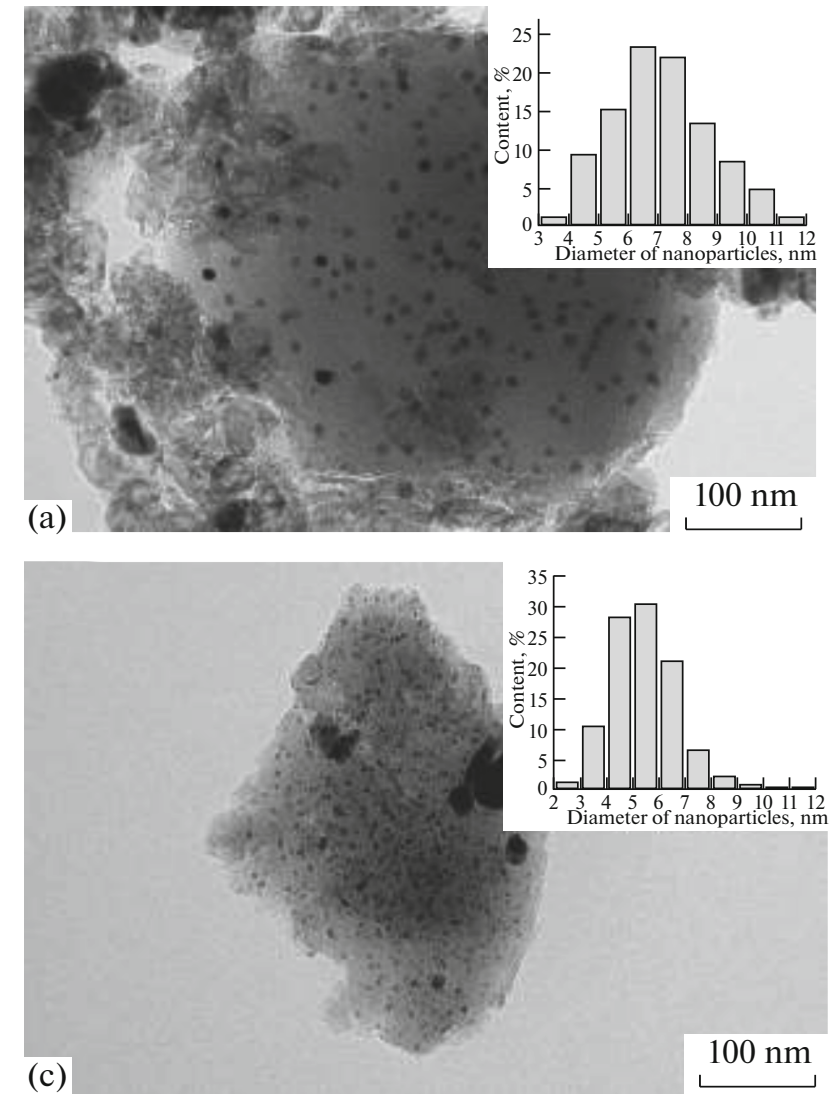

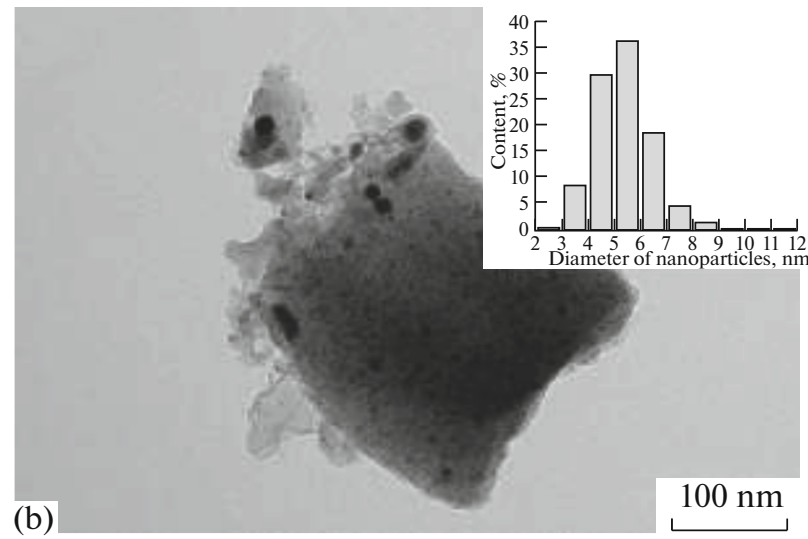

(b) $100 \mathrm{~nm}$

Fig. 2. TEM micrographs of (a) CS-Co, (b) CS-Co-Pd, and (c) CS-Pd samples.

ation of the process. An increase in the proportion of such carbon structures results in greater intensity and the formation of a more distinct maximum of the carbon peak in the region of $39^{\circ}$ in the diffractogram of the CS-Co nanocomposite.

The micrograph of the CS-Pd sample shows there was no notable amount of ordered graphite-like structures in the structure of the carbon support, confirming the data from XRD. The histogram of the size distribution of palladium nanoparticles shows that the main nanoparticle size was $5 \mathrm{~nm}$.

Raman spectroscopy was also used to characterize the CS-Co, CS-Co-Pd, and CS-Pd samples. Figure 3 shows the peaks at 1378 and $1595 \mathrm{~cm}^{-1}$ attributed to bands $D$ and $G$, respectively. Bands $D$ and $G$ correspond to the $s p^{3}$ - and $s p^{2}$-hybridization of carbon atoms, respectively. The difference between the spectra is confirmed by the data obtained via XRD and TEM. Our study thus showed the $I_{D} / I_{G}$ ratios for the CS-Co, CS-Co-Pd, and CS-Pd samples were 0.69 , 0.88 , and 0.93 , respectively. The lower value of the $I_{D} / I_{G}$ ratio for the CS-Co sample indicates a lower content of the structural defects that are characteristic of the more amorphous carbon matrix of the CS-Pd sample. The ordered graphite-like structures that formed in the presence of cobalt raised the intensity of band $G$, reducing the value of the ratio $I_{D} / I_{G}$. The height of the saddle in the area of $1500 \mathrm{~cm}^{-1}$, which could have formed due to intermediate bands or the overlay of $D$ and $G$ bands, should also be noted. A high saddle can indicate a considerable fraction of amorphous carbon in a sample, as is clearly seen for the that of CS-Pd. In contrast, the CS-Co sample is characterized by a relatively low saddle, since cobalt promoted the formation of the ordered carbon structures that are clearly visible in the micrograph in Fig. 2a.

The Raman spectrum for the CS-Co-Pd sample has an intermediate form and correlates with the data from XRD and TEM.

\section{CONCLUSIONS}

A one-step procedure for the synthesis of mono(Co, $\mathrm{Pd})$ and bimetallic (Co-Pd) nanoparticles and a carbon support based on carbonized chitosan was developed. Differences in the structure of the carbon support caused by the metal that was used were shown. In a bimetallic system, a support based on carbonized chitosan combines features of the carbon structure of 


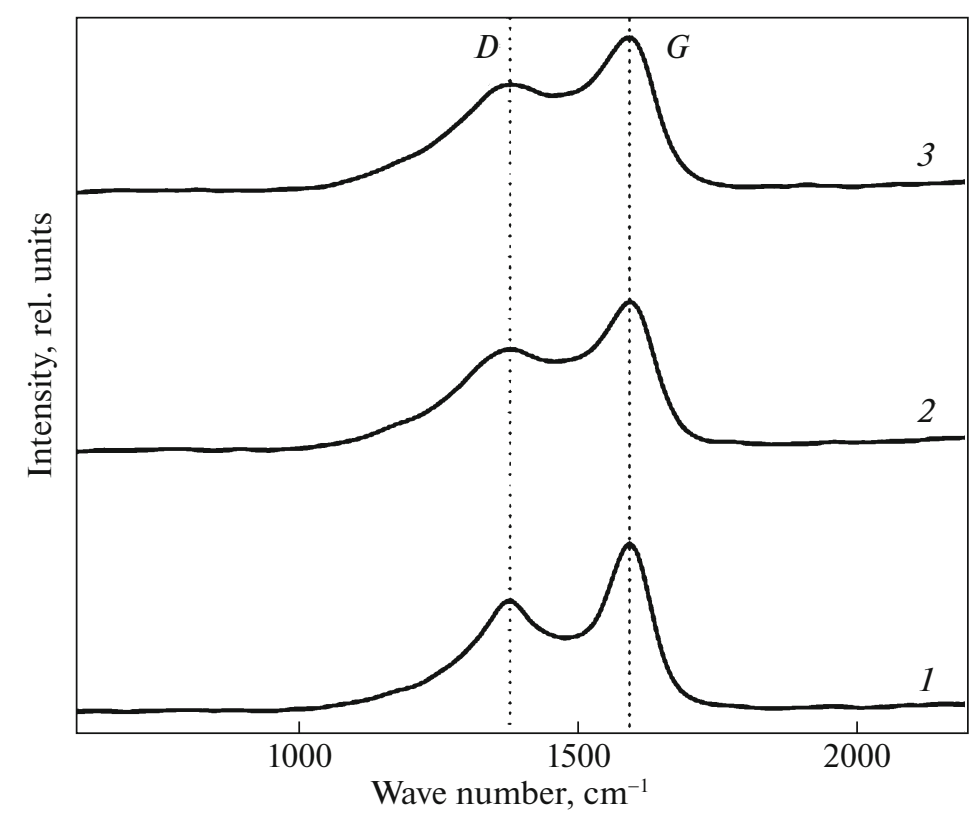

Fig. 3. Raman spectra for (1) CS-Co, (2) CS-Co-Pd, and (3) CS-Pd.

both monometallic systems. Adding palladium lowers the size of bimetallic nanoparticles, relative to monometallic cobalt.

\section{FUNDING}

This work was performed as part of a State Task for the Topchiev Institute of Petrochemical Synthesis, Russian Academy of Sciences.

\section{OPEN ACCESS}

This article is licensed under a Creative Commons Attribution 4.0 International License, which permits use, sharing, adaptation, distribution and reproduction in any medium or format, as long as you give appropriate credit to the original author(s) and the source, provide a link to the Creative Commons license, and indicate if changes were made. The images or other third party material in this article are included in the article's Creative Commons license, unless indicated otherwise in a credit line to the material. If material is not included in the article's Creative Commons license and your intended use is not permitted by statutory regulation or exceeds the permitted use, you will need to obtain permission directly from the copyright holder. To view a copy of this license, visit http://creativecommons.org/licenses/by/4.0/.

\section{REFERENCES}

1. A. Zaleska-Medynska, M. Marchelek, M. Diak, et al., Adv. Colloid Interface Sci. 229, 80 (2016). https://doi.org/10.1016/j.cis.2015.12.008

2. Y. Wang, Y. Zhao, J. Yin, et al., Int. J. Hydrogen Energy 39, 1325 (2014).

https://doi.org/10.1016/j.ijhydene.2013.11.002
3. F. Mauriello, H. Ariga-Miwa, E. Paone, et al., Catal. Today 357, 511 (2020). https://doi.org/10.1016/j.cattod.2019.06.071

4. D. Medina-Cruz, B. Saleh, A. Vernet-Crua, et al., in Racing for the Surface: Antimicrobial and Interface Tissue Engineering, Ed. by B. Li, T. F. Moriarty, T. Webster, and M. Xing (Springer Int., Cham, 2020), p. 397. https://doi.org/10.1007/978-3-030-34471-9_16

5. A. V. Chistyakov, M. V. Tsodikov, M. V. Chudakova, et al., Pet. Chem. 58, 32 (2018). https://doi.org/10.1134/S096554411801005X

6. A. A. Vasilev, M. N. Efimov, G. N. Bondarenko, et al., Chem. Phys. Lett. 730, 8 (2019). https://doi.org/10.1016/J.CPLETT.2019.05.034

7. M. Ragothaman, B. T. Mekonnen, and T. Palanisamy, Mater. Chem. Phys. 253, 123405 (2020). https://doi.org/10.1016/j.matchemphys.2020.123405

8. H. Borchert, B. Jürgens, T. Nowitzki, et al., J. Catal. 256, 24 (2008). https://doi.org/10.1016/j.jcat.2008.02.017

9. Y.-S. Feng, X.-Y. Lin, J. Hao, et al., Tetrahedron 70, 5249 (2014). https://doi.org/10.1016/j.tet.2014.05.083

10. O. G. Ellert, M. V. Tsodikov, S. A. Nikolaev, et al., Russ. Chem. Rev. 83, 718 (2014). https://doi.org/10.1070/RC2014v083n08ABEH004432

11. N. Firdous, N. K. Janjua, and M. H. S. Wattoo, Int. J. Hydrogen Energy 45, 21573 (2020). https://doi.org/10.1016/j.ijhydene.2020.05.167

12. G. Sharma, A. Kumar, S. Sharma, et al., J. King Saud Univ. - Sci. 31, 257 (2019). https://doi.org/10.1016/j.jksus.2017.06.012

13. N. Yang and S. F. Bent, J. Catal. 351, 49 (2017). https://doi.org/10.1016/j.jcat.2017.04.003

14. E. Lam and J. H. T. Luong, ACS Catal. 4, 3393 (2014). https://doi.org/10.1021/cs5008393 
15. F. Rodríguez-Reinoso, Carbon (N.Y.) 36, 159 (1998). https://doi.org/10.1016/S0008-6223(97)00173-5

16. Y.-J. Wang, B. Fang, H. Li, et al., Prog. Mater. Sci. 82, 445 (2016).

https://doi.org/10.1016/j.pmatsci.2016.06.002

17. G. Peng, F. Gramm, C. Ludwig, and F. Vogel, Catal. Sci. Technol. 5, 3658 (2015). https://doi.org/10.1039/C5CY00352K

18. C. Chen, Y. Chen, A. M. Ali, et al., Chem. Eng. Technol. 43, 719 (2020). https://doi.org/10.1002/ceat.201900508

19. E. Frecha, D. Torres, A. Pueyo, et al., Appl. Catal. A: Gen. 585, 117182 (2019). https://doi.org/10.1016/j.apcata.2019.117182

20. M. N. Efimov, A. A. Vasilev, D. G. Muratov, L. M. Zemtsov, and G. P. Karpacheva, Russ. J. Phys. Chem. A 91, 1766 (2017).

21. V. N. Selivanov and E. F. Smyslov, Crystallogr. Rep. 38, 382 (1993).
22. A. A. Vasil'ev, G. P. Karpacheva, E. L. Dzidziguri, et al., Inventor's Certificate No. 2019660702 (2019), p. 1.

23. M. N. Efimov, E. L. Dzidziguri, A. A. Vasiliev, D. G. Muratov, E. N. Sidorova, and G. P. Karpacheva, Russ. J. Phys. Chem. A 94, 1443 (2020).

24. A. A. Vasilev, M. N. Efimov, G. N. Bondarenko, et al., IOP Conf. Ser.: Mater. Sci. Eng. 693, 012002 (2019).

25. H. Marsh, D. Crawford, and D. W. Taylor, Carbon (N. Y.) 21, 81 (1983).

26. M. N. Efimov, E. L. Dzidziguri, E. N. Sidorova, K. O. Chuprunov, L. M. Zemtsov, and G. P. Karpacheva, Russ. J. Phys. Chem. A 82, 1175 (2008). https://doi.org/10.1134/S0036024408070212

27. E. L. Dzidziguri, M. N. Efimov, L. M. Zemtsov, et al., RF Patent No. 2597935, Request No. 2015123269, Byull. Izobret., No. 26 (2016). 